\title{
Control of Pediatric Viral Diseases: Past Successes and Future Prospects
}

\author{
ROBERT M. CHANOCK \\ Laboratory of Infectious Diseases, National Institute of Allergy and Infectious Diseases, National Institutes of \\ Health, Bethesda, Maryland 20892
}

This presentation is dedicated to Dr. Albert Sabin, one of the great heroes of 20 th century pediatric research, in recognition of his many significant contributions to the health of children and the distinction he has brought to American pediatrics and the American Pediatric Society.

This Centennial Meeting is an appropriate occasion to celebrate the important role American pediatrics has played in bringing a number of important viral diseases under control. Preventive medicine has been a major activity of the American Pediatric Society and its members have made a disproportionately large contribution to the development of safe, effective viral vaccines.

Currently, effective licensed vaccines are available for prevention of disease caused by 10 distinct human viruses or viral groups. The first of these vaccines, vaccinia virus, was developed by Jenner 190 years ago for the prevention of smallpox. Ninety years elapsed until the rabies virus vaccine was developed by Pasteur. During the last 50 years, the pace of discovery and development accelerated and vaccines for eight additional viruses or virus groups were added to our armamentarium. Members of the American Pediatric Society played an essential role in the development of vaccines for five of these eight viruses or virus groups: inactivated poliovirus vaccine, John Enders, Thomas Weller, and Frederick Robbins; live poliovirus vaccine, Albert Sabin; live measles virus vaccine, John Enders and Samuel Katz; live rubella virus vaccine, Harry Meyer and Stanley Plotkin; live adenovirus vaccine, Robert Chanock; and inactivated hepatitis $B$ virus (HBV) vaccine, Saul Krugman.

It should be noted that eight of the 10 viral diseases against which effective vaccines are now available are caused by viruses that produce a systemic infection. This is not surprising because small amounts of serum antibodies are usually highly effective in preventing disease caused by viruses that spread systematically. In contrast, the requirements for effective immunization against a topical infection in which virus produces its disease manifestations at the site of implantation are more demanding because locally produced mucosal antibodies and/or a high concentration of serum antibodies are needed for resistance.

\section{LIVE VIRUS VACCINES}

Except for the adenoviruses, type 2 poliovirus and vaccinia virus, the licensed live vaccine strains were attenuated during serial propagation in cell culture. Satisfactory attenuation and antigenicity of vaccinia, measles, mumps, rubella, and adenovirus vaccine strains were determined exclusively by clinical evaluation in susceptible individuals (1).

During the development of live vaccines for yellow fever and poliomyelitis, studies in experimental animals provided a strong signal that mutants with the desired phenotype and level of attenuation had been selected by passage of virus in cell culture or had been recovered directly from an asymptomatically infected individual. The I7D vaccine mutant of tissue cultureadapted yellow fever virus was identified by its decreased tropism for the liver of experimentally infected monkeys (2). Later, clinical studies indicated that the mutant was satisfactorily attenuated and antigenic in humans. Similarly, naturally occurring or laboratory-selected mutants of poliovirus with markedly reduced neurovirulence for the spinal cord were identified by studies in monkeys $(3,4)$. These candidate poliovirus vaccine strains were then subjected to additional cycles of selection that led to the identification of mutants that replicated with high efficiency in the intestinal tract without significant increase in neurovirulence for nonhuman primates. The optimal strains selected in this manner were then shown to be satisfactorily attenuated and antigenic in susceptible individuals.

The molecular basis for attenuation of the measles, mumps, and rubella virus vaccine strains is not known. It is known, however, for the live vaccine strains of type 1 and type 3 poliovirus. During the course of its attenuation, the type 1 strain sustained 56 nucleotide substitutions that resulted in 21 amino acid changes (5). Analysis of chimeric infectious cDNA constructed from the virulent parental type 1 virus and its attenuated vaccine derivative indicates that mutations responsible for attenuation are scattered throughout the $7.5 \mathrm{~kb}$ RNA viral genome (6). The type 3 vaccine strain sustained fewer mutations and this is thought to be the explanation for the fact that its attenuation is less stable than that of the type 1 vaccine strain. Ten nucleotide substitutions occurred in the type 3 vaccine strain resulting in only three amino acid changes (7). Molecular genetic analysis of the type 3 vaccine strain indicated that only two mutations play a prominent role in attenuation: a nucleotide substitution in the $5^{\prime}$ noncoding region of the genome and an amino acid substitution in the viral VP3 capsid protein $(8,9)$. The type 2 vaccine strain is a naturally occurring attenuated mutant and the basis of its attenuation is not known at this time.

During the course of its attenuation, the yellow fever virus $17 \mathrm{D}$ vaccine strain sustained 32 amino acid substitutions in its entire complement of viral proteins (10). It is perhaps significant that $40 \%$ of these mutations clustered in the viral envelope glycoprotein that is responsible for adsorption of virus to the host cell.

Finally, it should be noted that live virus vaccine strains do not necessarily have to be attenuated to produce an asymptomatic immunizing infection. An example of this apparent paradox is the live type 4 and type 7 adenovirus vaccine, which is now used routinely for prevention of adenovirus respiratory tract disease in military recruits $(11,12)$. During the development of this vaccine, we did not attempt to attenuate the vaccine strains. Instead, attenuation was achieved by confining infection to a region of the body in which symptoms fail to develop. Oral administration of enteric-coated type 4 and type 7 adenovirus produces a silent infection limited to the intestines. Infection does not spread back to the respiratory tract, which is the usual site of disease produced by these viruses. Ordinarily, adult vaccinees do not transmit infection to their close contacts.

The pace at which new vaccines are introduced into pediatric practice should accelerate during the next decade. Vaccines for 
seven additional viruses are imminent or in various stages of development. The most imminent is the live varicella virus vaccine that could be licensed within a few years $(13,14)$. Probably next in line is a live virus vaccine for rotavirus diarrheal disease.

\section{INACTIVATED VACCINES}

Before discussing the newer vaccines under development, many of which are live and attenuated, it should be noted that live viral vaccines offer several significant potential advantages over inactivated or subunit viral vaccines. However, a live viral vaccine is not suitable for every situation. For example, subunit vaccines are mandatory for viruses such as HIV and HBV that integrate into the host genome and cause persistent infection. Indeed, one of the major recent successes in pediatric immunoprophylaxis has been the inactivated hepatitis $B$ virus vaccine that contains purified HBV surface antigen (HBsAg). In one study, immunization of neonates with purified $\mathrm{HBsAg}$ reduced the frequency of transmission of $\mathrm{HBV}$ from highly infectious, chronically infected members ( $\mathrm{HBeAg}$ positive) to their infants by $89 \%$ (15). This protection was achieved without concurrent administration of hepatitis B immune globulin (HBIG) and in the face of a transmission frequency of $65 \%$ in the placebo group. Vaccine efficacy in this situation is of considerable public health importance because infants infected near or during delivery are at high risk of becoming chronic carriers of HBV and developing chronic hepatitis and/or primary hepatocellular carcinoma (16, 17).

Recently, several encouraging developments have suggested that effective immunization against respiratory syncytial virus (RSV) may be achievable with purified viral surface antigens (18). RSV F and G glycoproteins were purified from a lysate of infected cells by immunoaffinity chromatography, and immunization of cotton rats with either glycoprotein induced complete resistance to RSV infection in the lungs (18). There was no evidence of enhanced pulmonary pathology in the immunized animals following challenge with RSV. Clinical trials of a purified RSV F glycoprotein vaccine are now underway.

\section{ADVANTAGES AND DISADVANTAGES OF LIVE VIRUS VACCINES}

Among the advantages of live viral vaccines are induction of more effective local mucosal immunity and greater duration of immunity. Also, during infection, protective viral antigens are displayed in their mature configuration on the virus and in some instances on the surface of infected cells. Processed viral antigens are also displayed at the surface of infected cells. These features of antigen presentation favor the induction of an effective, balanced response of neutralizing antibodies and cell-mediated immunity. The most serious potential disadvantage of live viral vaccines is the possibility that genetic instability could lead to loss of attenuation.

\section{STRATEGIES EMPLOYED TO MINIMIZE GENETIC INSTABILITY}

Six different strategies are now being employed to minimize the possibility of genetic instability without compromising the proper balance between attenuation and immunogenicity required of all live viral vaccine strains.

Jennerian Approach. The first strategy is the Jennerian approach which involves the use of an animal or avian virus that is related antigenically to a human virus. Animal and avian viruses that are well adapted to their natural host often do not replicate efficiently in humans and hence are attenuated for man. This type of attenuation is usually quite stable as a consequence of the significant divergence of the animal or avian viral genes involved in host range restriction from the corresponding human viral genes.
Bovine parainfluenza type 3 virus. A recent example of the Jennerian approach is the bovine parainfluenza type 3 virus (bovine PIV3). Human parainfluenza virus type 3 is a paramyxovirus that is second in importance only to RSV as an etiologic agent of serious pediatric viral respiratory tract disease. Bovine PIV3 shares several neutralization epitopes with human PIV3 but these two viruses exhibit significant divergence of sequence $(19,20)$. Nonetheless, infection of cotton rats and monkeys with bovine PIV3 induces significant resistance to human PIV3 (21). Furthermore, bovine PIV3 is restricted in the lower respiratory tract of rhesus monkeys and chimpanzees (21). These encouraging observations concerning attenuation and protective efficacy provide a rationale for clinical evaluation of bovine PIV3 as a live vaccine for prevention of human PIV3 disease.

Modified Jennerian Approach for Use with Viruses Possessing a Segmented Genome. Avian x human influenza A virus reassortants. The Jennerian approach has recently been modified to take advantage of the segmented genome of some avian and animal viruses that are attenuated in humans. In this situation, attenuating genes that code for nonsurface proteins, so-called "internal genes," can be transferred by gene reassortment into a reassortant ("hybrid") virus that derives its genes for protective surface antigens from a related human virus. For example, the internal genes of influenza A virus are its three polymerase genes and the nucleoprotein, matrix protein, and nonstructural protein genes. These six internal genes of an avian influenza $A$ virus that is attenuated for experimental primates have been transferred into a reassortant virus that derived its genes for the hemagglutinin (HA) and neuraminidase (NA) protective surface antigens from a human influenza A virus (22). Reassortant viruses prepared by us in this manner from the attenuated avian influenza $A$ donor virus and a series of virulent human influenza $A$ viruses were as restricted in the lower respiratory tract of monkeys as the avian influenza $\mathrm{A}$ virus itself (23). In subsequent clinical trials in susceptible adults, and in some instances in infants and young children as well, these reassortant viruses have consistently been satisfactorily attenuated and immunogenic $(22,24)$.

Subsequent analysis indicated that four of the six internal avian influenza $\mathrm{A}$ virus genes played a role in host rangerestriction (25). The polygenic nature of avian influenza $A$ virus host range-restriction in humans is encouraging because it is unlikely that all of the avian influenza $\mathrm{A}$ virus genes responsible for attenuation could simultaneously develop the full complement of mutations required for human virulence, especially since avian influenza $A$ virus reassortants produce a restricted infection in susceptible humans (22).

Rotaviruses. Rotaviruses are the single most important group of etiologic agents of severe diarrhea of infants and young children throughout the world (26). Thus, the need for an effective rotavirus vaccine is now clear, particularly in developing countries where rotavirus disease appears to be a leading cause of mortality during the first two years of life. We are currently evaluating an animal rotavirus strain, rhesus rotavirus (RRV), as a vaccine candidate (26). This simian rotavirus has not been recovered under natural conditions from man and, thus, it is not a virus of human heritage. Although the genes of RRV exhibit significant divergence in sequence from the corresponding genes of human rotaviruses, this simian rotavirus is similar to human rotavirus serotype 3 when tested by neutralization (26).

Most promising are the results from a recent clinical trial in 247 young infants in Venezuela in which protective efficacy was $68 \%$ overall and $100 \%$ for the most severe forms of rotavirus diarrhea (27). In this study, the predominant rotavirus strain recovered from patients with diarrhea belonged to the same serotype as the vaccine virus. However, the vaccine proved to be ineffective in two other studies in which the predominant infecting strain belonged to a different serotype than RRV. This suggests that serotype-specific immunity is required in some circumstances for satisfactory protection against rotavirus diar- 
rhea. Because of the need for a multivalent vaccine that will induce resistance to each of the four human rotavirus serotypes, we modified the Jennerian approach by constructing reassortant viruses that contain $10 \mathrm{RRV}$ genes plus a single human rotavirus gene that codes for the major neutralization antigen (VP7) responsible for serotype specificity $(28,29)$. These single-gene substitution RRV reassortants with the attenuation characteristics of the rhesus virus and the neutralization specificity of human rotavirus serotype 1,2 , or 4 are now being evaluated in phase 1 and phase 2 clinical trials. To date, the reassortants appear to be as attenuated and immunogenic as RRV. RRV and its reassortants induce a transient febrile response in approximately one third of 2- to 6-month-old vaccinees. However, fever does not occur when RRV is fed during the first month of life, but the vaccine is still immunogenic.

Another animal rotavirus, bovine strain WC3 (serotype 6), has also been studied as a candidate live vaccine for prevention of rotavirus disease. Initial results have been encouraging and the live attenuated vaccine strain has been shown to provide significant protection against rotavirus disease caused predominantly by serotype 1 virus (30).

Use of Naturally Attenuated Human Viruses. More than 33 years ago, Albert Sabin observed that strains of poliovirus recovered from healthy individuals exhibited a wide range of neurovirulence as measured by intracerebral or intraspinal inoculation of monkeys $(3,4)$. Approximately one fifth of these strains were highly attenuated. In fact, the type 2 strain of the live oral poliovirus vaccine was identified in this manner.

Rotaviruses. Rotaviruses cause a wide spectrum of effects ranging from asymptomatic infection in neonates to severe dehydrating diarrheal illness in older infants and young children, but the degree of virulence is not serotype specific because each of the four distinct human rotavirus serotypes has been associated with silent as well as symptomatic infections. During the past few years, rotavirus strains have been recovered from prolonged outbreaks of infection in newborn nurseries in which most affected infants failed to develop significant symptoms. The basis for this naturally occurring attenuation appears to be the fourth rotavirus gene which is highly conserved among asymptomatic nursery strains of all four serotypes $(31,32)$. This conserved sequence differs significantly from the conserved fourth gene sequence of virulent rotaviruses of all four serotypes. The product of the fourth gene is a major surface protein (VP4). This protein must be cleaved proteolytically in the intestines for rotavirus to become infectious. The nursery strains of human rotavirus are currently in clinical trial to determine their potential usefulness in prevention of rotavirus disease.

Experimentally Produced Deletion Mutants. Attenuation of viral virulence by a deletion mutation of appreciable size has a theoretical appeal because this form of mutation cannot be corrected directly inasmuch as this would require restoration of deleted sequence. Viable deletion mutations can now be produced at specific sites in the genome of DNA viruses, (herpes simplex, adenovirus) or positive-strand RNA viruses (poliovirus). However, it has not been possible to produce specific viable deletions in negative-strand RNA viruses (influenza, RSV) or double-strand RNA viruses (rotaviruses).

Some viable deletion mutants of herpes simplex virus are markedly attenuated for experimental animals (33). Latency is also reduced but is not completely abolished. Fortunately, molecular mechanisms responsible for latency of herpes viruses are now coming into focus and these insights may provide a basis for constructing attenuated deletion mutants that are unable to establish latency. Using a similar strategy, it may be possible to abolish latency of the live varicella vaccine strain.

Experimentally Produced Viable Chimeric Viruses. Recently viable intertypic chimeras (hybrids) of poliovirus were constructed using infectious cloned cDNA. The nucleotide sequence for one of the three antigenic sites of type 3 poliovirus was substituted for the corresponding site of type 1 poliovirus in a type 1 infectious cDNA clone $(34,35)$. The resulting chimeric virus has dual antigenic specificity. Substitution of the entire outer protein surface of type 3 virus for the corresponding region of type 1 virus has also been accomplished yielding a chimeric virus that is solely type 3 in antigenic specificity (36).

Most of the very rare live poliovirus vaccine-associated paralytic illnesses $\left(\approx 1\right.$ in $10^{6}$ immunizations) have been linked to the type 3 vaccine strain. Hence, an intertypic type 1-type 3 chimera that is type 1 in sequence except for one antigenic site of type 3 virus or the entire type 3 surface region may prove useful in immunoprophylaxis because it combines type 3 serologic specificity with the greater observed genetic stability of the type 1 vaccine strain.

Experimental Production or Selection of Single Base Substitution ("Missense") Mutants. Cold-adapted influenza A virus mutant. Previous attempts to produce stable attenuated missence mutants of RSV and influenza A virus for use in immunoprophylaxis all met with failure. More encouraging results have been obtained with a cold-adapted $(c a)$ mutant of influenza A virus which was selected by John Maassab et al. (37). Transfer of the six internal genes of the $c a$ influenza A/Ann Arbor donor mutant to viruses bearing the surface glycoprotein genes of new antigenic variants of influenza $A$ virus regularly attenuates the resulting reassortant viruses for susceptible human volunteers (37). Furthermore, $c a$ reassortants induce resistance to experimental challenge with virulent human influenza $A$ virus that is equal to or greater than that induced by licensed inactivated influenza $A$ vaccine (38). Four of the six internal genes of the $c a$ donor virus are independently involved in attenuation (39). The involvement of multiple genes in attenuation provides a likely explanation for the observed stability of the attenuation phenotype of $c a$ influenza virus reassortants during infection of humans.

Attenuated Viral Vectors that Express Genes Coding for Protective Antigens of Other Viruses. The sixth approach to the development of safe, effective live vaccines involves the use of a stable attenuated vaccine virus to construct viable recombinants that express the protective antigens of other viruses. To date, the most success has been achieved using vaccinia virus as the recombinant vector (40). This virus has a large genome with a variety of genes into which foreign viral genes can be inserted and expressed without seriously compromising vaccinia's capacity to replicate. Equally important, vaccinia virus has the longest record of successful use as an effective, attenuated live virus vaccine.

Adenoviruses also have the potential to serve as recombinant vectors for construction of live vaccines because they have a large genome with at least one "nonessential" region as well as several sites into which foreign genes can be inserted and expressed without loss of infectivity (41). In addition, safe, effective live adenovirus vaccine strains that produce a silent, selective intestinal infection are available for use as viral vectors $(11,12)$.

Respiratory syncytial virus $(R S V)$, parainfluenza virus type 3 $(P I V 3)$, and dengue virus. The potential of live recombinant viruses for prevention of viral disease is perhaps best illustrated by initial success in developing an experimental vaccine for prevention of disease caused by RSV. The challenge of vaccination against RSV disease is formidable because the virus has its major impact during the second and third months of life. Thus, we face the difficult task of immunizing very young infants, perhaps newborns. Unfortunately, this is a difficult period in which to attempt immunization because the infant's immunologic processes are not fully responsive to antigenic stimulation. Also, RSV serum antibodies, which are passively acquired from the mother, act to suppress the infant's immunologic response to the protective antigens of RSV (42).

Previous attempts to develop a safe and effective live or inactivated RSV vaccine have all met with failure. Recent experience with vaccinia virus-RSV glycoprotein recombinants offers hope that effective immunization against RSV can be achieved in the near future. Vaccinia virus recombinants expressing the 
protective antigens of RSV were constructed by inserting the gene for the RSV G or F surface glycoprotein into the thymidine kinase (TK) gene of vaccinia $(43,44)$.

Cotton rats infected intradermally with either vaccinia-RSV recombinant developed a high level of specific antibodies that neutralized RSV infectivity with high efficiency $(43,44)$. Infection of cotton rats or owl monkeys with both vaccinia-RSV recombinants stimulated complete resistance in the lower respiratory tract to subsequent challenge with $\operatorname{RSV}(44,45)$. VacciniaPIV3 surface glycoprotein recombinants were also effective in inducing resistance to PIV 3 in the lungs of cotton rats and monkeys (46).

Dengue viruses have importance in pediatrics because these viruses cause epidemics that involve infants and children in most tropical and semitropical regions of the world. In some of these regions dengue hemorrhagic fever/shock syndrome is a leading cause of mortality for infants and young children. Recent experience with vaccinia virus-dengue virus recombinants suggests that immunoprophylaxis may soon be possible. This optimism stems from the observation that infection of mice with a vaccinia virus recombinant that expresses either of the two protective glycoprotein antigens of dengue virus, or both antigens together, induces solid resistance to an intracerebral challenge with 100 $\mathrm{LD}_{50}$ of virus (47).

Safety of vaccinia virus recombinants. The observations just described are encouraging, but many pediatricians have expressed a concern for safety because of the serious complications associated with vaccinia virus that occur approximately once in 100000 immunizations. However, in my view, it is likely that the frequency of such complications will be considerably less for vaccinia recombinants. Vaccinia recombinants are constructed by inserting a foreign gene into a vaccinia gene that is not required for virus replication in cell culture. Nonetheless, insertional inactivation of any of these nonessential genes regularly causes attenuation of a virulent strain of vaccinia for experimental animals. The extent of attenuation varies considerably for the different insertion sites (40).

My concern is that recombinants prepared from an already attenuated licensed vaccinia virus strain suitable for use in humans might be overattenuated and thus suffer an unacceptable decrease in immunogenicity. This issue can only be resolved by studies in which vaccinia virus recombinants prepared from a licensed strain of vaccinia virus are evaluated in clinical trials, starting with recombinants that are potentially most attenuated and progressing to less attenuated recombinants until satisfactory immunogenicity is achieved. The vaccinia virus recombinant system can also be fine-tuned by coexpression of lymphokine IL-2 that independently causes attenuation without reduction of immunogenicity (48). IL-2 is remarkable because it markedly attenuates virulent vaccinia even in mice lacking functional $T$ cells.

\section{FUTURE}

The future for prevention of pediatric viral diseases is very bright indeed. At this time of celebration, we should allow our imagination to run free in an attempt to predict the many new wonders that will be reported at the bicentennial celebration of the American Pediatric Society.

\section{REFERENCES}

1. Chanock RM, Murphy BR, Collins PL, Coelingh KVW, Olmsted RA, Snyder MH, Spriggs MK, Prince GA, Moss B, Flores J, Gorziglia M, Kapikian AZ 1988 Live viral vaccines for respiratory and enteric tract diseases. Vaccine $6: 129-134$

2. Theiler M 1951 The virus. In: Strode GK (ed) Yellow Fever. McGraw-Hill, New York, pp 39-137

3. Sabin AB 1956 Present status of attenuated live-virus poliomyelitis vaccine. JAMA 162:1589-1596

4. Sabin AB 1957 Properties and behavior of orally administered attenuated poliovirus vaccine. JAMA 164:1216-1223

5. Nomoto A, Omata T, Toyoda H, Kuge S, Horie H, Kataoka Y, Genba Y,
Nakano Y, Imura N 1982 Complete nucleotide sequence of the attenuated poliovirus Sabin 1 strain genome. Proc Natl Acad Sci USA 79:5793-5797

6. Nomoto A, Kohara M, Kuge S, Kawamura N, Arita M, Komatsu T, Abe S, Semler BL, Wimmer E, Itoh H 1987 Study on virulence of poliovirus type 1 using in vitro modified viruses. In: Brinton MA, Ruckert RR (eds) Positive Strand RNA Viruses. Alan R Liss, New York, pp 437-452

7. Almond JW, Cann AJ, Minor PD, Reeve P, Schild GC, Hauptmann R, Stanway G 1983 Nucleotide sequence from neurovirulent and attenuated strains of poliovirus type 3. Rev Infect Dis 6:5487-5493

8. Evans DMA, Dunn G, Minor PD, Schild GC, Cann AJ, Stanway G, Almond JW, Currey K, Maizel Jr JV 1985 Increased neurovirulence associated with a single nucleotide change in a noncoding region of the Sabin type 3 polio vaccine genome. Nature 314:548-550

9. Westrop GD, Evans DMA, Minor PD, MaGrath DI, Schild GC, Almond JW 1986 Investigation of the molecular basis of attenuation in the Sabin type 3 vaccine using novel recombinant polioviruses constructed from infectious cDNA. In: Rowlands DJ, Mayo MA, Mahy BWJ (eds) The Molecular Biology of the Positive Strand RNA Viruses. Academic Press, New York, pp $53-60$

10. Hahn CS, Dalrymple JM, Strauss JH, Rice CM 1987 Comparison of the virulent Asibi strain of yellow fever virus with the $17 \mathrm{D}$ vaccine strain derived from it. Proc Natl Acad Sci USA 84:2019-2023

11. Chanock RM, Ludwig W, Heubner RJ, Cate TR, Chu L-W 1966 Immunization by selective infection with type 4 adenovirus grown in human diploid tissue culture. I. Safety and lack of oncogenicity and tests for potency in volunteers. JAMA 195:445-452

12. Edmondson WP, Purcell RH, Gundelfinger BF, Love JWP, Ludwig W, Chanock RM 1966 Immunization by selective infection with type 4 adenovirus grown in human diploid tissue culture. II. Specific protective effect against epidemic disease. JAMA 195:453-459

13. Gerson AA, Steinberg SP, LaRussa P, Gerrara A, Hammerschlag M, Gelb L, NIAID Varicella Vaccine Collaborative Study Group 1988 Immunization of healthy adults with live attenuated varicella vaccine. $J$ Infect Dis 158:132137

14. Takahashi M 1988 Varicella vaccine. In: Plotkin SA, Mortimer EA (eds) WB Saunders, Philadelphia, pp 526-548

15. Xu Z, Chung-bo L, Francis DP, Purcell RH, Zhi-Li G, Chen-hsiang H, Maynard JE, US-PRC Cooperative Study Group on Hepatitis B 1985 Prevention of perinatal acquisition of hepatitis B virus (HBV) carriage using vaccine: preliminary report of a randomized, double-blind placebo-controlled and comparative trial. Pediatrics 76:713-718

16. Beasley RP 1982 Hepatitis B virus as the etiologic agent in hepatocellular carcinoma-epidemiologic considerations. Hepatology 2:21S-26S

17. Beasley RP, Hwang LY, Lin CC, Chien SC 1981 Hepatocellular carcinoma and HBV: a prospective study of 22,707 men in Taiwan. Lancet 2:11291133

18. Walsh EE, Hall CB, Briselli M, Brandriss MW, Schlesinger JJ 1987 Immunization with glycoprotein subunits of respiratory syncytial virus to protect cotton rats against viral infection. J Infect Dis 155:1 198-1204

19. Coelingh KWV, Winter CC, Murphy BR 1987 Antigenic relationships between the hemagglutinin-neuraminidase glycoproteins of human and bovine type 3 parainfluenza viruses. In: Chanock RM, Lerner RA, Brown F, Ginsberg $\mathrm{H}$ (eds) Vaccines 87: Modern approaches to new vaccines including prevention of AIDS. Cold Spring Harbor Laboratory, New York, pp 296 -301

20. Suzu S, Sakai Y, Shioda T, Shibuta H 1987 Nucleotide sequence of the bovine parainfluenza 3 virus genome: the genes of the $\mathrm{F}$ and $\mathrm{HN}$ glycoproteins. Nucleic Acids Res 15:2945-2958

21. Coelingh KLVW, Winter CC, Tierney EL, London WT, Murphy BR 1988 Attenuation of bovine parainfluenza virus type 3 in nonhuman primates and its ability to confer immunity to human parainfluenza virus type 3 challenge. J Infect Dis 157:655-662

22. Murphy BR, Buckler-White AJ, London WT, Harper J, Tierney EL, Miller NT, Reck LJ, Chanock RM, Hinshaw VS 1984 Avian-human reassortant influenza A viruses derived by mating avian and human influenza A viruses. J Infect Dis 150:841-850

23. Murphy BR, Sly DL, Tierney EL, Hosier NT, Massicot JG, London WT, Chanock RM, Webster RG, Hinshaw VS 1982 Influenza A reassortant virus derived from avian and human influenza $A$ virus is attenuated and immunogenic in monkeys. Science 218:1330-1332

24. Murphy BR, Snyder MH, Buckler-White AJ, Clements ML, Betts RF, London WT, Chanock RM 1987 Avian-human influenza A virus reassortants as live virus vaccines in humans. In: Mahy B, Kolakofsky D (eds) The Biology of Negative Strand Viruses. Elsevier, New York, pp 404-411

25. Tian SF, Buckler-White AJ, London WT, Reck LJ, Chanock RM, Murphy BR 1985 Nucleoprotein and membrane protein genes are associated with restriction of replication of influenza A/Mallard/NY/78 virus and its reassortants in squirrel monkey respiratory tract. J Virol 53:771-775

26. Kapikian AZ, Midthun K, Hoshino Y, Flores J, Wyatt RG, Glass RI, Askaa J, Nakagomi O, Nakagomi T, Chanock RM, Levine MM, Clements ML, Dolin R, Wright PF, Belshe RB, Anderson EL, Potash L 1985 Rhesus of rotavirus: a candidate vaccine for prevention of human rotavirus disease. In: Lerner R, Chanock RM, Brown F (eds) Vaccines 85. Cold Spring Harbor Laboratory, New York, pp 357-366

27. Flores J, Perez-Schael I, Gonzalez M, Garcia D, Perez M, Daoud N, Cunto W, Kapikian AZ 1987 Protection against severe rotavirus diarrhea by rhesus rotavirus vaccine in Venezuelan infants. Lancet 1:882-884

28. Midthun K, Hoshino Y, Kapikian AZ, Chanock RM 1986 Single gene substi- 
tution rotavirus reassortants containing the major neutralization protein (VP7) of human rotavirus serotype 4. J Clin Microbiol 24:822-826

29. Midthun K, Greenberg HB, Kapikian AZ, Wyatt RG, Chanock RM 1985 Reassortant rotavirus as potential live vaccine candidates. J Virol 53:949954

30. Clark HF, Borian FE, Bell LM, Modesto K, Gouvea V, Plotkin SA 1988 Protective effect of WC3 vaccine against rotavirus diarrhea in infants during a predominantly serotype I rotavirus season. J Infect Dis 158:570-587

31. Flores J, Midthun K, Hoshino Y, Green K, Gorziglia M, Kapikian AZ, Chanock RM 1986 Conservation of the fourth gene among rotaviruses recovered from asymptomatic newborn infants and its possible role in attenuation. J Virol 60:972-979

32. Gorziglia M, Green K, Nishikawa K, Taniguchi K, Jones R, Kapikian AZ, Chanock RM 1988 Sequence of the fourth gene of human rotaviruses recovered from asymptomatic or symptomatic infections. J Virol 62:29782984

33. Meignier B, Longnecker R, Mavromara-Nazos P, Sears AE, Roizman B 1988 Virulence of and establishment of latency by genetically engineered deletion mutants of herpes simplex virus 1. Virology 162:251-254

34. Burke KL, Dunn G, Ferguson M, Minor PD, Almond JW 1988 Antigen chimeras of poliovirus as potential new vaccines. Nature 332:81-82

35. Murray MG, Kuhn RJ, Arita M, Kawamura N, Nomoto A, Wimmer E 1988 Poliovirus type 1/type 3 antigenic hybrid virus constructed in vitro elicits type 1 and type 3 neutralizing antibodies in rabbits and monkeys. Proc Natl Acad Sci USA 85:3203-3207

36. Nomoto A, lizuka N, Kohara M, Arita M 1988 Strategy for construction of live picornavirus vaccines. Vaccine 6:134-137

37. Maassab HF, LaMontagne JR, DeBorde DC 1988 Live influenza virus vaccine. In: Plotkin SA, Mortimer EA (eds) Vaccines. WB Saunders, Philadelphia, pp 435-437

38. Clements ML, Betts RF, Tierney EL, Murphy BR 1986 Resistance of adults to challenge with influenza $A$ wild-type virus after receiving live or inactivated virus vaccine. J Clin Microbiol 23:73-76

39. Snyder MH, Betts RF, DeBorde D, Tierney EL, Clements ML, Herrington D Sears SD, Dolin R, Maassab HF, Murphy BR 1988 Four viral genes independently contribute to attenuation of live influenza A/Ann Arbor/6/60 (H2N2) cold-adapted reassortant virus vaccines. J Virol 62:488-495
40. Moss B, Flexner C 1987 Vaccinia virus expression vectors. Ann Rev Immunol 5:305-324

41. Morin JE, Lubeck MD, Barton JE, Conley AJ, Davis AR, Hung P 1987 Recombinant adenovirus induces antibody response to hepatitis $\mathrm{B}$ virus surface antigen in hamsters. Proc Nat1 Acad Sci USA 84:4626-4630

42. Murphy BR, Alling DW, Snyder MH, Walsh EE, Prince GA, Chanock RM Hemming VG, Rodriquez WJ, Kim HW, Graham BS, Wright PF 1986 Effect of age and preexisting antibody on serum antibody response of infants and children to the $F$ and $G$ glycoproteins during respiratory syncytial virus infection. J Clin Microbiol 24:894-898

43. Elango N, Prince GA, Murphy BR, Venkatesan S, Chanock RM, Moss B 1986 Resistance to human respiratory syncytial virus (RSV) infection induced by immunization of cotton rats with a recombinant vaccinia virus expressing the RSV G glycoprotein. Proc Natl Acad Sci USA 83:1906-1910

44. Olmsted RA, Elango N, Prince GA, Johnson PR, Moss B, Chanock RM, Collins PL 1986 Expression of the F glycoprotein of respiratory syncytial virus by a recombinant vaccinia virus: comparison of the individual contributions of the $F$ and $G$ glycoproteins to host immunity. Proc Natl Acad Sci USA 83:7462-7466

45. Olmsted RA, Buller RML, Collins PL, London WT, Beeler JA, Prince GA, Chanock RM, Murphy BR 1988 Evaluation in nonhuman primates of the safety, immunogenicity and efficacy of recombinant vaccinia viruses expressing the $F$ or $G$ glycoprotein of respiratory syncytial virus. Vaccine 6:519524

46. Spriggs MK, Collins PL, Tierney E, London WT, Murphy BR 1988 Immunization with vaccinia virus recombinants that express the surface glycoproteins of human parainfluenza virus type 3 (PIV3) protects patas monkeys against PIV3 infection. J Virol 62:1293-1296

47. Bray M, Falgout B, Zhao B, Markoff L, Moss B, Chanock RM, Lai CJ 1989 Mice immunized with recombinant vaccinia virus expressing dengue 4 structural proteins and/or nonstructural protein NSl are protected against fetal dengue encephalitis. In: Lerner RA, Ginsberg H, Chanock RM, Brown $\mathrm{F}$ (eds) Vaccines 89: Modern Approaches to New Vaccines Including Prevention of AIDS. Cold Spring Harbor Laboratory, New York, pp 357-362

48. Flexner C, Hugin A, Moss B 1987 Prevention of vaccinia virus infection in immunodeficient mice by vector-directed IL-2 expression. Nature 330:259261 